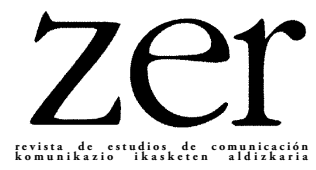

\title{
Revistas iberoamericanas sobre Comunicación
}

\author{
Komunikazioari buruzko aldizkari iberoamerikarrak \\ Latin American Journals of Communication \\ Udane Goikoetxea Bilbao* \\ Universidad del País Vasco/Euskal Herriko Unibertsitatea
}

\section{Introducción}

Las revistas sobre comunicación que publican en castellano, proponen diversos temas no siempre novedosos. Analizan tanto la comunicación como las nuevas tecnologías aplicadas a diversas situaciones y la cultura de masas. Algunas de las revistas no han publicado ningún número durante 2018. Tal es el caso de CIC Cuadernos de Información y Comunicación, de la Universidad Complutense de Madrid, Discursos Fotográficos de la Universidade Estadual de Londrina Paraná, Documentación de las Ciencias de la Información de la Universidad Complutense de Madrid, Enl@ce: Revista Venezolana de Información, Tecnología y Conocimiento de Maracaibo, Universidad del Zulia, o Transinformaçao de la Pontificia Universidade Católica de Campinas en Brasil.

^ Correspondencia a: Udane Goikoetxea Bilbao. Fac. CC. Sociales y de la Comunicación, barrio Sarriena, s/n (48940 Leioa).udane.goikoetxea@ehu.eus http://orcid.org/0000-0002-9844-5221

Cómo citar: Goikoetxea Bilbao, Udane. 2018. Revistas iberoamericanas sobre Comunicación. Zer. 23(45). 227-249.

https://doi.org/10.1387/zer.20307

Recibido: 23 octubre 2018; aceptado: 23 octubre 2018

1137-1102 y 1989-631X / C 2018 UPV/EHU

(c) (1) Esta obra está bajo una licencia Creative Commons Atribución 4.0 Internacional 
En este trabajo mencionamos los artículos publicados en el resto (28), de las 33 revistas listadas en años anteriores ordenadas alfabéticamente. Algunos de los temas desarrollados por dichos artículos aunque son conocidos, presentan nuevos o renovados puntos de vista sobre temáticas tales como las referidas a la crisis económica, Google, el consumo o los riegos que conlleva la difusión de contenidos en las redes como Instagram. Los temas estrella son diferentes aspectos sobre las redes sociales, publicidad en su relación tanto con la educación como con la comunicación, los entornos transmedia o el tratamiento de las noticias en los medios. Algunas de las revistas han publicado números monográficos. Son reseñables los publicados por Historia y Comunicación Social de la Universidad Complutense de Madrid sobre «1917. Revolución y comunicación", o el de la revista Icono 14 de Madrid que plantea como objetivo reposicionar el periodismo de datos iberoamericano dentro de las investigaciones internacionales en este campo. Por su parte Obra Digital edita un monográfico que se centra en los retos y oportunidades que las Relaciones Públicas están viviendo en nuestros días, especialmente en lo que concierne a un mundo interconectado, los nuevos medios de comunicación y los medios sociales en diferentes ámbitos de actuación. La Revista Mediterránea de Comunicación Universidad de Alicante, divulga dos monográfico. El primer monográfico es sobre Educomunicación y promoción de la salud y explora la eficiencia de los hospitales españoles en producción científica como indicador de transferencia de Conocimiento, la competencia tecnológica y habilidades relacionadas con las Tecnologías de la Información y la Comunicación (TIC) de los adultos maduros, las construcciones del género en tiempos de Internet como modos de expresión y riesgos percibidos en las redes sociales durante la niñez o la gamificación y transformación de la escuela. También se abordan temáticas prosociales e impacto de una intervención educativa Flipped Classroom relacionada con la promoción de la salud mediante la creación relatos audiovisuales y un estudio sobre la importancia de Informar y concienciar sobre cáncer basado en el caso de la Asociación Española Contra el Cáncer en Facebook. Finaliza con un artículo sobre la representación de la salud en la publicidad audiovisual de Manos Unidas mediante un análisis de contenido de las campañas institucionales de 1995 a 2017. El segundo monográfico, que versa sobre la generación LED abarca temas como la educomunicación, competencias mediáticas y smartphones o sobre el uso crítico de los medios en la formación universitaria. Las competencias parentales positivas y Smartphones; diagnóstico en el contexto familiar sobre la generación millennial, las autorrepresentaciones y rasgos comunicativos de las interacciones de jóvenes en Tinder.

El número de la revista Trípodos (Llenguatge, Pensament, Comunicació de la Universitat Ramon Llull de Barcelona) es un monográfico sobre el cine negro, «thriller» y policíaco español desde una perspectiva histórica.

El blog de la revista Comunicar publicaba en junio de 2016 los resultados para las Revistas Iberoamericanas en JCR, según los cuales «Comunicar se posiciona como la única revista iberoamericana de Ciencias Sociales en Primer Cuartil, y una 
de las 20 revistas de Comunicación con mayor impacto del mundo ${ }^{1}$ ». El resto o la mayor parte de ellas, según la misma fuente, pertenecen a la base de datos Science Citation Index. Además, se encuentran posicionadas en tercer y cuarto cuartil. Afirman también que de los países que publican, España tiene revistas mejor posicionadas y cuenta con mayor presencia de revistas de Ciencias Sociales. Posteriormente los resultados se mantienen igual en líneas generales.

\section{1. Ámbitos. REVISTA INTERNACIONAL DE COMUNICACIÓN \\ (Sevilla: Universidad de Sevilla, GREHCCO, núm. 41, 2018)}

El primer artículo toma como estudio de caso el entorno mediático malagueño para la adaptación de los periodistas y las empresas de medios al uso de la denominada "cuarta pantalla». Se presenta también la importancia de la caricatura y el grafiti como medio de comunicación en la Primavera Árabe Siria. Dos artículos nos trasladan a México: el estudio transversal de metodología mixta titulado «Persecución criminal en México y su influencia en la hipermediación: un estudio de caso» y un segundo que profundiza en la formación de profesores como esfuerzo de alfabetización digital en México. En el último abordan la turbotemporalidad y la omnipantalla que son presentados como los nuevos paradigmas de acción en el mundo actual y que es necesario comprender sus mecanismos de cara a poder potenciar el pensamiento crítico del siglo XXI.

\section{ANALES DE DOCUMENTACIÓN}

(Murcia: Universidad de Murcia, vol. 21, núm. 1, 2018)

La revista incluye artículos que presentan una propuesta sobre el copyfraude que analiza las prácticas desarrolladas por un conjunto de bibliotecas digitales españolas pertenecientes a las Administraciones públicas para divulgar sus colecciones patrimoniales en Dominio público.

Continúa con un análisis sobre el rol crucial que ocupan las bibliotecas universitarias españolas en el contexto actual como soporte para la investigación. Su objetivo es ofrecer una visión global de cuáles son los servicios de apoyo a la investigación prestados por las bibliotecas vinculadas a REBIUN. El siguiente artículo tiene como propósito presentar el estado del arte realizado para el proyecto de investigación Doctoral «La incidencia de la biblioteca en la reducción de las desigualdades sociales: el caso del Sistema de Bibliotecas Públicas de la ciudad de Medellín a partir del Acuerdo 079 de 2010». También presenta la gestión de la comunidad biblio-

\footnotetext{
1 https://revistacomunicar.wordpress.com/2016/06/14/las-revistas-iberoamericanas-en-jcr-2015/
} 
tecaria en cuanto a la información en paralelo con otros sectores profesionales del mundo web. Finaliza con un artículo cuyo objeto de estudio es indagar en las vicisitudes de la conocida biblioteca gimnástico-deportiva del Gimnasio Colón (18921906). Asimismo se analiza la trascendencia de esta biblioteca y del Catálogo del Gimnasio Colón (1935) en su época.

\section{AnÀlisi (Quaderns de Comunicació y Cultura)}

(Barcelona: Universitat Autònoma de Barcelona, núm. 58, 2018)

En su número 58, Anàlisi incluye artículos sobre la ampliación de los paisajes de la narración televisiva en el entorno de los medios digitales del siglo Xxi, la cobertura de noticias de la radio comunitaria en los medios europeos mediante un mapeo de temas populares y silencios importantes como identificar qué tipo de problemas es más probable que se informen en los medios, así como las realidades desconocidas en las que aún están inmersos. También un análisis que pretende establecer la relación entre la calidad de las noticias y el género de la información, atendiendo a los protagonistas de las noticias y a las fuentes informativas. Un artículo que aborda una nueva forma de aplicar la narración en el marketing, que lo usa para extender productos repasando la importancia general de la narración de historias como una herramienta y estrategia de comunicación. El siguiente artículo titulado «La función del pathos en el storytelling del documental publicitario» investiga el documental como formato del contenido de marca a fin de analizar sus características narrativas como estrategia de comunicación publicitaria. Un artículo que se centra en dos trabajos del italiano Igort, "Cuadernos ucranianos» y «Cuadernos rusos», que describen las atrocidades del Holodomor y la guerra ruso-chechena y reflexiona sobre el problema de la distancia respecto a sus fuentes y a la realidad misma, cuestión central en cualquier relato histórico, periodístico o documentalista. Incluye un análisis sobre las narrativas hegemónicas de la violencia. El crimen organizado y el narcotráfico entre el periodismo y las ficciones televisivas. Finaliza con un artículo que partiendo del caso mexicano que propone una revisión de las repercusiones de estas narrativas periodísticas en las series televisivas de ficción Gomorra (2014), Narcos (2015) y El Chapo (2017). También está presente Chile con un artículo que reflexiona sobre qué memorias sobre el pasado reciente de Chile construye la generación que vivió el golpe de estado (de 50 a 64 años) a partir de sus lecturas de series ficcionales y por qué estas memorias entran en conflicto en la esfera pública.

4. ÁREA ABIERTA

(Madrid: Universidad Complutense de Madrid, vol. 18, núm. 2, 2018)

Este último número de Área Abierta centra sus contenidos en las diferentes representaciones de la crisis. El primer trabajo describe las películas recientes «Los exámenes», 
«Dos días y una noche» $\mathrm{y}$ «Capital humano» que cuentan historias que revelan diversas facetas de la crisis económica y cómo el cine de autor ilumina los aspectos más oscuros del fenómeno social. Sigue con un artículo que trata de analizar en qué medida las seis producciones cinematográficas de viajes espaciales, estrenadas entre 2013 y 2018, han contribuido la renovación del concepto de sueño americano durante una de sus peores crisis. También podemos encontrar una revisión de la mirada filmica en torno a la crisis de la posmodernidad, tomando como punto de partida el análisis de sociólogos posmodernos de relieve y se repasan las tendencias filmicas dominantes de los 80 y 90 . Además, el trabajo atiende a la experimentación de un giro en esta tendencia a comienzos del milenio, expresada en el cine múltiplex como exponente de este cambio. Sigue con un artículo que propone estudiar las cinco películas que componen la franquicia La jungla de cristal (1988-2013) mediante un acercamiento multidisciplinar. También un artículo que tiene como objetivo explicar la razón por la que la película «El hijo de Saúl» volvió a reabrir una crisis sobre lo representable y no representable del Holocausto debido a lo novedoso de su planteamiento ético y estético. Continúa con un artículo sobre la descripción de las crisis (socio) políticas nacionales a las que se enfrentan los presidentes norteamericanos de ficción en ejemplos de series televisivas Kennedy (1983) y The West Wing (19992006). Incluye un trabajo sobre la representación de la crisis española en la publicidad en la campaña «Despertar» (Campofrío, 2015). Y un texto que trata de establecer unas nociones generales sobre la aplicación del Big Data a diversos ámbitos que interactúan con la disciplina de la Comunicación en el contexto de la Cuarta Revolución Industrial. Otro titulado «Imágenes en la Crisis Mediterránea: la creación de la imagen pública de Nasrallah» que propone analizar la imagen de Nasrallah como líder carismático de Hezbollah, a partir de la definición de Weber y las aportaciones de House. Finaliza con un resumen de una investigación sobre los orígenes, evolución y crisis del sistema de exhibición cinematográfica en el Teatro Principal de Zamora durante sus años de existencia como sala de cine (1897-1984) desde la etapa finisecular del XIX a su cierre.

\section{COMUNICACIÓN Y SOCIEDAD \\ (Guadalajara, México: Universidad de Guadalajara, núm. 33, 2018)}

Este número está dedicado al Alfabetismo transmedia, propuesta que abarcaba tanto la formación crítica para el consumo mediático como la creación de un periódico o radio escolar. Incluye un artículo sobre el concepto de alfabetización transmedia en el ámbito educativo mediante la revisión de la literatura. Continúa con una investigación transnacional sobre alfabetismos digitales con el objetivo de estudiar las prácticas de lectoescritura juvenil de estudiantes de colegios públicos colombianos en relación a las de narraciones transmedia. Un estudio que presenta los principales hallazgos de la investigación Transliteracy para Uruguay en relación al objetivo de identificar estrategias de aprendizaje informal de habilidades que los adolescentes 
desarrollan a través de prácticas transmedia. A continuación recoge un estudio sobre usos mediáticos y prácticas de producción con adolescentes de Portugal, España e Italia. En el siguiente artículo se analiza el proceso de creación y difusión de videos que desarrollan niños YouTubers peruanos para comprender el tipo de habilidades que se despliegan en dicho proceso a través del método de la etnografia digital. También un trabajo que revela la emergencia de nuevos alfabetismos transmediales basados en una ética Do It Yourself bajo el título «De la alfabetización a los alfabetismos: aprendizaje y participación DIY de Fans y Makers mexicanos». En este número podemos encontrar un artículo que describe y analiza la validez de «Viaje al Centro de la Radio» como propuesta de alfabetización transmedia que pretende promover la cultura radiofónica entre los jóvenes en el entorno digital. Y otro que presenta la experiencia de una narrativa transmedia en una escuela secundaria de Argentina con el objetivo de reflexionar sobre las implicaciones en el proceso educativo. Finaliza analizando la experiencia pedagógica \#Orson80, una propuesta de narrativa transmedia educativa que se inserta en la currícula escolar y que a la vez genera producciones que exceden las paredes del aula.

\section{COMUNICACIÓN Y SOCIEDAD}

(Pamplona: Universidad de Navarra, vol. 31, núm. 3, 2018)

El primer artículo aborda el tema de la comunicación política actual en un escenario de tecnologías digitales, participación ciudadana y gobernanza abierta. Pone como ejemplo la salida inesperada de los británicos de la Unión Europea, la crisis migratoria, el ascenso de Isis, los conflictos en países como Siria, el surgimiento del populismo y las reacciones ciudadanas imprevistas (el rechazo del Plan de Paz de Colombia o la elección del presidente Trump) y afirma que todos tienen en común la incertidumbre que trae consigo y que caracteriza la era actual. El segundo artículo tiene como objetivo analizar el uso de Twitter por parte de los actores políticos españoles para construir su agenda durante las campañas electorales. En el tercero también están presentes las elecciones españolas de 2016; en este caso el objetivo de la investigación es examinar qué tipo de expresión electrónica de los ciudadanos se puede encontrar al comentar los mensajes de Facebook de los líderes de los partidos políticos en el contexto de una elección. Sigue con un artículo sobre el uso del contenido viral en la comunicación de la política y aborda el caso del ex primer ministro croata, Ivo Sanader. Dos artículos tienen como tema central el populismo. Uno analiza los elementos centrales del populismo centrándose en los Partidos populistas en Europa occidental. Y el otro analiza la calidad del discurso en los tiempos del populismo mediante un análisis de los debates parlamentarios alemanes sobre la política de inmigración. Incluye un trabajo sobre tres actitudes políticas, eficacia interna, eficacia externa e interés político en el contexto de Chile. El siguiente artículo tiene como eje dos requisitos de las emisoras de servicio público en España; la participación cívica e independencia del poder político. También presenta el impacto de las 
redes sociales en la agenda parlamentaria europea con respecto a la guerra Siria. Seguidamente recoge un documento que explora el poder de la representación en el contexto del futuro incierto de los inmigrantes indocumentados en los Estados Unidos. El último artículo del especial habla sobre el uso de algoritmos de aprendizaje supervisado en comunicación política y estudios de medios.

En la miscelánea encontramos artículos sobre el tratamiento informativo de las víctimas, victimarios y demandas punitivas en la Argentina, un artículo que explora la obra del director argentino Lisandro Alonso a partir de la figura del hombre nómade, del errante contemporáneo que ya no encuentra lugar en las ciudades moderna. Otro sobre el impacto de las plataformas globales en la competencia mediática y los resultados de las empresas de comunicación europeas. Sigue con un artículo que presenta el Instituto Cervantes analizando la comunicación del mismo a través de la red Twitter durante un periodo determinado. Y entre otros un artículo que ahonda en el «Decreto Miró» y su repercusión en la producción de películas relacionadas con la violencia de ETA (1983-1989).

\section{COMUNiCAR. REVISTA CIENTÍfiCA IBEROAMERICANA DE COMUNICACIÓN Y EDUCACIÓN}

(Huelva: Grupo Comunicar, vol. XXVI , núm. 56, octubre 2018)

Con el título «Artivismo: Arte y compromiso social en un mundo digital» el dossier central de la revista tiene estudios sobre principales experiencias en artivismo para reflexionar sobre la utilidad del mismo como nuevo lenguaje social y como herramienta educativa capaz de romper los roles tradicionales de la comunicación social. El primer artículo presenta el artivismo de la mano del compromiso social para transformar la formación del profesorado desde la sensibilidad. También presenta un análisis sobre la forma, el contenido y el engagement generado por las fotografias y el uso que se hace en ellas de la figura del niño de las fotografias publicadas en Instagram a lo largo del año 2017 por las 20 ONG más relevantes a nivel internacional. Incluye un trabajo sobre la cultura del posdrama en Ecuador y España y una indagación teórica de los fundamentos del videoartivismo, con el objetivo de realizar una delimitación conceptual bajo el título «Videoartivismo: Poética del conflicto simbólico».

La sección Caleidoscopio incluye un trabajo que tiene como objetivo definir los patrones de consumo, creación y difusión de contenidos audiovisuales de Internet en los ámbitos del ocio y las fuentes de información complementarias para uso escolar de los jóvenes guipuzcoanos, atendiendo a las variables de género, curso y tipo de centro. También un artículo que presenta la relación entre preadolescentes y youtubers, con el objetivo de observar cómo los primeros integran a los youtubers como referentes de una cultura digital juvenil. Continúa con un artículo que desa- 
rrolla ideas y genera nuevas líneas de investigación sobre las vidas digitales de los niños en China y Australia. Finaliza con un trabajo sobre la formación universitaria sobre el emprendimiento en proyectos empresariales de comunicación y periodismo y otro titulado «Los estudios sobre radio: Un balance desde la academia iberoamericana» que efectúa una aproximación a la situación de los «radio studies iberoamericanos» desde la perspectiva de su comunidad científica que se centra en las trayectorias, percepciones y valoraciones en torno a la investigación radiofónica en una esfera supranacional, con características comunes pero importantes divergencias en el abordaje de la comunicación como ámbito de estudio.

\section{CUADERNOS.INFO}

(Santiago de Chile: Pontificia Universidad Católica de Chile, núm. 42, 2018)

Las investigaciones de la revista están centradas en Social media, branding y consumo. El primer artículo aborda el tema de la figura del en las redes sociales como un nuevo modelo de líder de opinión que debe combinar la gestión de su marca personal con el rol de prescriptor, incluyendo los mensajes de contenido político analizando el contenido de mensajes de diez influencers españoles con alto impacto en Twitter. El siguiente trabajo reflexiona sobre la programación de la creación mediante una exploración al campo socio-técnico de YouTube en Chile. «El uso de Twitter en las marcas de moda de lujo frente a las denominadas low-cost» es un análisis de contenido de 1.135 tuits publicados por H\&M, Zara, Ralph Lauren y Hugo Boss. Y también están presentes las estrategias de gestión de los clubs de golf públicas, privadas o comerciales de la Comunidad de Madrid en Twitter.

\section{DOXA. COMUNICACIÓN: REVISTA INTERDISCIPLINAR DE ESTUDIOS DE COMUNICACIÓN Y CIENCIAS SOCIALES}

(Madrid: Universidad San Pablo-CEU, núm. 26, 2018)

La revista publica trabajos sobre las acciones de comunicación que realizan las ONG españolas de apoyo al Sáhara, las oportunidades que brinda el uso de drones al relato informativo en España, las campañas contra el castigo físico a menores en España y propuesta de estrategias para el cambio de actitudes, la utilidad de las herramientas y métricas de audiencia surgidas en el entorno digital para desarrollar prácticas comunicativas de Inbound Marketing, el uso cuantitativo y cualitativo de Twitter por parte de los principales candidatos durante las campañas electorales españolas de 2011 y 2015 para plantear si existe una brecha digital entre los candidatos de la «vieja»y «nueva» política, La formación para la gestión de las redes sociales en los grados de comunicación en España y su adecuación a las competencias demandadas por las organizaciones, Frames de la religión en editoriales de cuatro periódicos españoles 
(2009-2010), un estudio de caso sobre las Unidades de Cultura Científica y de la Innovación $(\mathrm{UCC}+\mathrm{i})$ españolas en la prensa digital, la inmersión del espectador en el reportaje en $360^{\circ}$ mediante análisis comparativo de «En la piel de un refugiado» y «Fukushima, vidas contaminadas», y cómo afrontar las noticias falseadas (fake news) en los medios de comunicación y en las redes sociales mediante la alfabetización periodística.

\section{ESTUDIOS SOBRE EL MENSAJE PERIODÍSTICO}

(Madrid: Universidad Complutense de Madrid, vol. 24, núm. 1, 2018)

Esta publicación presenta artículos sobre el femicidio en la prensa ecuatoriana mediante un análisis de contenido de los diarios El Univers y El Comercio, la tercera edad en los contenidos informativos de la prensa digital que estudia los encuadres noticiosos sobre las personas mayores de Castilla y León, y un estudio basado en los editoriales de la prensa española El País, El Mundo y ABC (1994-2014) que afirma que tras la publicación en 1995 de la Ley de Prevención de Riesgos Laborales, la mayor cantidad de editoriales se deriva de graves accidentes en el periodo de máxima siniestralidad en España. El propósito del siguiente trabajo es saber, a través de un análisis de contenido cuantitativo, el tratamiento informativo desde el plebiscito sobre los acuerdos de paz en Colombia, hasta el día en que Juan Manuel Santos gana el premio Nobel de Paz. Continúa con el análisis del tratamiento de la información económica en los códigos éticos y deontológicos en el entorno español. Además explora la presencia de los elementos constitutivos del género negro en los textos que no pueden considerarse puramente literarios y reportajes publicados por Rosa Montero en El País sobre el atentado de Atocha, ocurrido en 1977. Continúa con un estudio que rescata la figura de Jacinto Ontañón (1845-1917), primer periodista profesional de Burgos y un análisis del periodismo de datos en la campaña electoral del 20 de diciembre de 2015 a través de las ediciones digitales de diarios generalistas. También cuenta con un estudio que afirma que la hipótesis de la comercialización periodística sostiene que la creciente presión de la prensa por rentabilizar su actividad la lleva a relegar aspectos sustanciosos de cobertura política por encuadramientos de tipo estratégico, de juego o de interés humano, particularmente durante las elecciones. Incluye una propuesta socio-crítica para investigar las culturas periodísticas a partir de la revisión de «Worlds of Journalism Study» (20122015) y un análisis sobre la televisión informativa en el entorno digital de las ediciones diarias de las cadenas generalistas líderes de audiencia en España. Se analiza la percepción profesional de la eficacia de los mecanismos tradicionales de autorregulación periodística en el nuevo contexto del periodismo y también se analiza el peso de la influencia de los gobiernos en las informaciones de la prensa de calidad. El objetivo del siguiente artículo ha sido indagar cuáles serían los criterios selectivos más apropiados para aplicar a los documentos fotoperiodísticos. En este número se incluye un trabajo de la biblioteca digital sobre Donald Trump «Fact-checking frente 
a fake news». Otra investigación analiza la biblioteca digital creada por la Fundación del Internet Archive sobre Donald Trump, incluye más de 700 discursos, entrevistas y debates del Presidente de los EEUU. A continuación se afirma que importantes transformaciones políticas, sociales y tecnológicas ocurridas durante las últimas décadas han afectado a los sistemas de medios, así como a la profesión periodística en Latinoamérica. Otro artículo parte de la hipótesis de que un bajo porcentaje de periodismo interpretativo perjudicaría la calidad de la información política y podría fomentar la apatía ciudadana hacia la política. El objetivo en otro artículo es doble: demostrar las restricciones de los procesos de integración horizontal en el sector periodístico, así como analizar los desaciertos cometidos por Vocento en su estrategia de diversificación multimedia. Otro trabajo analiza la tipología de fuentes informativas que emplean seis medios de la prensa española cuando tratan el tema de la ley de extranjería para determinar la proporción de la presencia de fuentes oficiales y de la sociedad civil. Se aborda la profesión periodística ante sus retos éticos como la autorregulación profesional y comunicativa frente a regulación en el caso español. En el siguiente trabajo de investigación se plantea la hipótesis de que los medios de comunicación generalistas no cuentan con una estrategia para informar sobre inmigración. Otro artículo analiza el nacimiento y evolución, trascendencia y situación actual de la prensa étnica, surgida en torno a los inmigrantes en España. Continúa con análisis de los factores y rasgos comunes presentes en una muestra de textos periodísticos sobre ciencia aparecidos en las ediciones online de tres diarios hispanoparlantes de referencia (La Nación de Argentina, El País de España y El Universal de México) en 2010, 2012 y 2014. Finaliza con el análisis de prensa argentina y chilena: casos José López y Caval. Esta publicación también da cuenta de Investigaciones y otros documentos.

\section{HISTORIA Y COMUNICACIÓN SOCIAL}

(Madrid: Universidad Complutense, vol. 23, núm. 1, 2018)

El Monográfico titulado «1917. Revolución y comunicación» abre este número con una investigación que parte de la invisibilidad de la mujer en la Revolución Rusa. También abarca artículos sobre el retorno de los españoles refugiados en la Unión Soviética mediante el análisis de las noticias aparecidas en los medios de la época nacional e internacional, los diferentes aspectos de la política de comunicación sobre el tópico «las mujeres y la revolución rusa», una hipótesis de que la teoría de la comunicación persuasiva de masas tiene su origen en el inicio del siglo xx, durante la I Guerra Mundial y especialmente en la Revolución Bolchevique y un trabajo sobre las relaciones entre el arte y la política en Rusia durante la revolución de 1917. También presenta el impacto de revolución rusa en el campo cordobés mediante una aproximación desde la prensa y las Actas Capitulares de los ayuntamientos, o las formas de creación visual que se generan en el período que comprende la Revolución Bolchevique atendiendo al soporte propagandístico del cartel bajo el título «La influencia del 
formalismo en el cartel bolchevique». Bajo el título «Desde Rumanía al frente soviético: los periodistas» se indaga sobre varios artículos de quiénes combatieron contra el comunismo en suelo ruso en los años cuarenta, el ejemplo más claro es la obra $\mathrm{Ru}$ manía. El siguiente artículo versa sobre las guerras de la memoria en Rusia que propone un acercamiento a las implicaciones políticas, para el presente y el futuro, de la «elección» de una determinada memoria histórica. Y un ensayo bibliográfico que propone ofrecer una panorámica histórica, política y social de la revolución de octubre de 1917. La revista también incluye artículos sobre las redes anarquistas en la Europa de posguerra, la información gubernamental en las páginas de apertura de sección en la prensa de referencia. También presenta la crónica como una tradición periodística y literaria latinoamericana. Un trabajo sobre la figura del judío en el cine franquista como El mito errante. En este número se presentan también un artículo sobre los fundamentos del concepto de desinformación como práctica manipuladora en la comunicación política y las relaciones internacionales y un artículo sobre las publicaciones sobre la organización del Frente de Juventudes (1940-1961) que hace referencia al adiestramiento de las mujeres en las actividades de la naturaleza.

\section{IBERSID \\ (Zaragoza: Universidad de Zaragoza, vol. 12, núm.1, 2018)}

Esta revista anual de gestión de la información pública investigaciones sobre «Buenas prácticas en la declaración de obras huérfanas en Europa», un análisis de los proyectos europeos de preservación y digitalización del patrimonio cultural. Incluye un trabajo sobre la percepción de las revistas científicas españolas hacia el acceso abierto, open peer review y altmetrics y otro sobre los archivos eclesiásticos como fuentes para el estudio de la beneficencia en España. Además se hace una evaluación de impacto de los recursos informativos bibliotecarios en la competitividad académica de 33 universidades públicas mexicanas acreditadas y un análisis de las noticias sobre lectura digital en cuatro periódicos portugueses Jornal de Notícias, Diário de Notícias, Correio da Manha y Público (2009-2011) utilizando la base de datos Factiva de especial relevancia. Finaliza con una contribución de la alfabetización informacional en el contexto académico a la Ciencia Abierta y una propuesta de un sistema de gestión integrado para fondos documentales patrimoniales familiares (FDPF).

\section{ICONO 14}

(Madrid: Icono14.net-Asociación Científica de Investigación de las NNTT de la Educación, vol. 16, núm. 2, 2018)

Este monográfico de la revista ICONO 14 tiene como objetivo reposicionar el periodismo de datos iberoamericano dentro de las investigaciones internacionales en este campo, para recontextualizar la contribución que realiza en los debates sobre el 
papel de esta práctica periodística. En el monográfico se publican trabajos sobre los resultados de una investigación realizada sobre la startup Politibot, un chatbot o bot conversacional especializado en contenidos políticos, surgido durante la campaña electoral de junio de 2016 en España a través de Telegram. En otro artículo se muestra la necesidad de desarrollar modelos en el uso y representación de datos aplicable a campos como la educación y el empoderamiento. El artículo «Periodismo de datos y transparencia al margen de los grandes medios, un estudio comparativo de Civio y ProPublica» hace un análisis comparativo de entrevistas con profesionales del periodismo de datos en la americana ProPublica y la española Civio. Los artículos de investigación incluidos en este número presentan la importancia del papel de las TIC, internet y redes sociales en el campo de la comunicación política electoral a través del caso de las elecciones de los diputados de ultramar de la República Dominicana del 2012 o una investigación que estudia las informaciones periodísticas sobre Google, desde la perspectiva de la teoría del encuadre (framing). También presenta la importancia del proceso colectivo basado no solamente en la acción artística como forma de conocimiento sino también como aprendizaje y comprensión de una realidad social en la que quedamos sumergidas. Otra basada en el proyecto europeo Erasmus+ Artivism: artistic practices as instruments for social transformation que se focaliza en los problemas de participación social de los jóvenes y la ciudadanía activa. Otro trabajo analiza la oferta de unas webradios que, con independencia de posibilitar la escucha de una programación más o menos regular en streaming o podcasting, que se caracterizan por compartir con su audiencia una amplia gama de contenidos complementarios multimedia. En el siguiente artículo muestra que las ONGD consideran importante la figura del Community manager y que incluyen las redes sociales Facebook y Twitter en los planes estratégicos de comunicación. Además del monográfico, la revista incluye trabajos de investigación sobre el tiempo en la fotografia mediante una revisión de conceptos forjados por autores relevantes Benjamin (1931), Barthes (1980) o Dubois (1986). Bajo el título «Prosumo, Swarming y Transmedia» se afirma que la storytelling transmedia representa hoy una auténtica revolución comunicativa, también un nuevo modelo de negocio. Finaliza con un estudio que afirma que la inmersión y emersión en los juegos digitales es importante en las últimas décadas, ya que la computación ubicua y los dispositivos geolocalizados han desdibujado el límite entre el espacio digital y el físico transformado la forma en que experimentamos ambos.

\section{INFORMAÇÃO \& SOCIEDADE: ESTUDOS}

(Brasil: Universidade Federal da Paraíba, vol. 28, núm. 2, 2018)

Recoge artículos de revisión sobre el modelo de metadatos Dublin core (19952015), uno que presenta las transformaciones que está teniendo Catálogos Online de Acceso Público (OPAC) debido al desarrollo tecnológico y por una supuesta exigencia de usuarios acostumbrados con servicios más interactivos proporcionados por la Web 2.0 y un análisis del discurso de la dimensión cultural de la ISKO, la Socie- 
dad Internacional para la organización del conocimiento. En el siguiente artículo presenta la relación mutua entre elementos de la creatividad y competencia en información y otro sobre las áreas de actuación del bibliotecario en el mundo de la publicación y las competencias técnicas y comportamentales necesarias para ello; la presencia del bibliotecario en el mercado editorial ha sido percibida, principalmente, en periódicos científicos y en editoriales comerciales y universitarias, pero de forma aún muy modesta, son pocos los bibliotecarios que actúan en la editorial, lo que puede ocurrir debido a la falta de conocimiento por parte del mercado editorial de las diversas. Finaliza con una revisión de literatura que reúne aspectos importantes para ampliar la discusión sobre los rankings, debate los indicadores más utilizados y principales críticas a los rankings universitarios league tables.

\section{InFOrmaCión, Cultura y SOCIEDAD}

(Argentina: Instituto de Investigaciones Bibliotecológicas de la Facultad de Filosofia y Letras de la Universidad de Buenos Aires, núm. 38, 2018)

Este número recoge un artículo sobre la profesionalización de la Filosofía en la Argentina a través de sus revistas: notas para la confección de un corpus hemerográfico, el estado del acceso abierto en publicaciones científicas emergentes del Ecuador. Continúa con las preferencias de investigadores y prácticas institucionales/disciplinares en la difusión y socialización de los resultados de investigación que tiene como objetivo realizar un aporte al conocimiento de las prácticas y preferencias de los docentes-investigadores de instituciones universitarias al momento de difundir y socializar sus publicaciones en repositorios institucionales de acceso abierto y en redes sociales académicas, partiendo de la premisa de que dicho fenómeno está influenciado tanto por la disciplina, como por la pertenencia institucional. Incluye un análisis de grupos de investigación de la Universidad de La Sabana sobre la visibilidad científica y académica en la web 2.0. Finaliza con un artículo sobre el estado de los repositorios institucionales venezolanos y sus revistas científicas y otro sobre el uso del archivo desde la perspectiva de los usuarios, centrado en el Archivo Nacional Histórico de Chile.

\section{OBRA DIGITAL}

(España: Universidad de Vic-Universidad Central de Cataluña, núm. 15, 2018)

El foco de este monográfico se centra en los retos y oportunidades que las Relaciones Públicas están viviendo en nuestros días, especialmente en lo que concierne a un mundo interconectado, los nuevos medios de comunicación y los medios sociales en diferentes ámbitos de actuación. En el primer artículo se hace un análisis exploratorio de las empresas vitivinícolas nacionales cuyas acciones desinteresadas en beneficio 
de su entorno, en especial vinculadas con la RSC y la filantropía, se divulgaron entre 2008 y 2015 en Twitter, Facebook, blogs, Página web o medios de comunicación social. Otro artículo expone los resultados de un análisis efectuado sobre una muestra de herramientas de comunicación que el sector inmobiliario viene desarrollando al albor del desarrollo de las TIC y en el marco de una reconfiguración estratégica de la comunicación institucional. Aborda el papel de las redes sociales en la relación con los públicos internos de las organizaciones. Continúa con una investigación de carácter exploratorio que permite diagnosticar la importancia que las organizaciones no gubernamentales para el desarrollo (ONGd) dan a la "comunicación». Y un estudio que se centra entre los años 2011-2013, período en el cual España estaba inmersa en un escenario de crisis para indagar sobre quiénes fueron los actores y los discursos que participaron del proceso de construcción de Opinión Pública respecto de los desahucios en España. Presenta un análisis de la estrategia de Responsabilidad Social Corporativa (RSC) dirigida a la comunidad local mediante el caso de una multinacional. En la miscelánea encontramos dos artículos: uno sobre la comunicación web y análisis económico financiero en el sector del transporte en el caso Busmet y un análisis del Diseño Corporativo en la moda española que analiza los logotipos de las 54 empresas españolas incluidas en la Asociación de Creadores de Moda de España (ACME) .

\section{PALABRA CLAVE}

(Bogotá: Facultad de Comunicación Social de la Universidad de La Sabana, vol. 21, núm. 3, 2018)

Este número especial de Palabra Clave busca dar cuenta del estado del campo de estudio y sus transformaciones en Iberoamérica. El primer artículo aborda el tema de las redes de citación como elemento de construcción del campo científico de la comunicación política en México. Otro titulado «Voces independientes de noticieros emprendedores: estableciendo una nueva agenda en Latinoamérica» que recoge los antecedentes y las razones por las cuales la independencia es considerada una innovación necesaria en el periodismo latinoamericano. Continúa analizando el framing político realizado por la televisión y la prensa durante la campaña electoral de Nuevo León, México en el 2015. Sigue con un estudio de caso de las elecciones generales españolas de 2015 titulado «Los debates electorales, ¿el último reducto frente la mediatización?» que tiene como objetivo observar qué temas destacaron en las intervenciones de los actores políticos y determinar si la mediatización afecta el contenido de los debates electorales, o si, por el contrario, estos espacios se mantienen como foros para la discusión detallada de diversas cuestiones de política pública. Incluye tres publicaciones sobre las redes sociales. En primer lugar habla sobre la campaña a la Alcaldía de Manizales (Colombia) en Twitter para comprender la interacción en línea entre candidatos y ciudadanos. En segundo lugar recoge un análisis de opinión pública durante las elecciones del año 2014 en Brasil con el fin de investigar los medios compartidos y la preferencia electoral de los ciudadanos en Twitter. Y en 
tercer lugar plantea un análisis de la concordancia y las estrategias temáticas del Centro Democrático en Twitter.

\section{Pensar la PUblicidad. REVISTA InTERnACIONAL DE INVESTIGACIONES PUBLICITARIAS \\ (Valladolid: Universidad de Valladolid-Universidad Complutense de Madrid, vol. 11, 2017)}

La revista divulga investigaciones sobre el origen, las propiedades y tipología del eslogan o la fórmula verbal muy empleada en la comunicación comercial y política, una aproximación historiográfica sobre el primer museo dedicado al arte publicitario creado en España, MUVAP (2001-2016). Continúa con la historia de vida, publicidad y ficción sobre Steve Jobs tratando de hacer entender cómo fue la construcción de un mito como proposición estratégica de consumo del brandscape Apple. A continuación se analiza la presencia de la técnica del Product placement y su evolución desde el comienzo del videoclip hasta la actualidad. El siguiente artículo indaga en la publicidad de los medios de comunicación que son, por definición, soportes de una publicidad consustancial a su existencia. El objetivo del siguiente artículo es conocer el alcance, dimensiones y futuro del patrocinio, así como diferenciarla del branded content. Finaliza con una aproximación a la actuación entre anunciantes y creativos en el nuevo contexto para tratar de entender las áreas formativas que se están exigiendo a los profesionales de la creatividad publicitaria.

\section{PeRspeCtiVAS EM CIÊNCIA DA INFORMAÇÃO}

(Brasil: Escola de Ciencia da Informacao da UFMG, vol. 23, núm. 3, 2018)

El número incluye artículos sobre ontología para la representación de tiempo en el contexto de indicadores de rendimiento, un estudio sobre cuál es el mejor estándar de metadatos que presenta un mapeo relacional entre los principales patrones de metadatos utilizados por los repositorios de objetos de aprendizaje y también incluye un artículo sobre la influencia de factores individuales en el uso de bibliotecas digitales centrado en el caso del Portal de Periódicos de Capes. Sigue con la evolución de la producción científica sobre la epistemología en el área de Ciencia de la Información que busca presentar autores de destaque y principales referenciales. Se analizan las prácticas innovadoras en las bibliotecas de Florianápolis en torno a las ideas de ciberativismo y de vigilancia cívica a través de las denominadas «redes sociales». Un estudio sobre la aplicabilidad de la Política archivística de preservación digital en instituciones públicas federales. El objetivo del siguiente artículo consiste en analizar el compartir y la protección del conocimiento en una empresa de innovación, del sector sucroenergético. Se presenta la etnometodología como un concepto teórico ade- 
cuado a la investigación sobre lectura, especialmente en lo que se refiere al género de los cómics de superhéroes. Y un artículo cuyo objetivó es analizar la Inteligencia Competitiva en el contexto de la Innovación en una industria global del sector automotriz de vehículos pesados.

\section{PERspeCtiVAs DE LA COMUNiCACIÓN}

(Chile: Facultad de Educación, Ciencias Sociales y Humanidades de la Universidad de La Frontera, vol. 11, núm. 1, 2018)

Este número difunde artículos sobre Comunicación y literatura desde una perspectiva transatlántica. Se reflexiona sobre si el populismo debiese ser considerado sólo como un fenómeno puramente político o si puede ser también estudiado desde una perspectiva cultural. Un ensayo enfoca en dos obras altamente representativas sobre el sur de Italia: el libro de Franco Arminio Terracarne (2011) y el filme documental de Gianfranco Rosi «Fuocoammare (2016). En «Observando a Europa observar sus fronteras» se hace autorreflexión cultural y vigilancia en filmes sobre migración. El siguiente artículo indaga en el análisis de la sociedad española que realizaron tres intelectuales republicanos, Francisco Ayala, Max Aub y Vicente Llorens, en sus primeras vueltas al país después de décadas en el exilio. A continuación se realizar una pequeña contribución al debate en relación al significado de ser europeo en el momento actual. También divulga artículos sobe la representación del rol de la mujer en el discurso gubernamental chileno (1990-2016) o la agenda política en el periodismo y los medios digitales en Chile. Otro titulado «Visualidad colonial sobre el Nuevo Mundo. Representación e imaginario del Reino de Chile en los grabados de Alonso de Ovalle (siglo XVII)» y finaliza con un análisis de la representatividad de los desahucios y de los desahuciados en la sociedad española actual tratando de identificar y determinar hasta qué punto el relato de los desahuciados y sus circunstancias sirven de epítome de los discursos de la crisis.

\section{ReVista InTERnacional de Relaciones Públicas \\ (Málaga: Universidad de Málaga, vol. 8, núm. 15, 2018)}

La revista publica trabajos referentes a la comunicación de crisis de Barcelona tras el atentado terrorista para conocer cómo gestionó Barcelona Turisme su comunicación de crisis durante y después del atentado de agosto de 2017 a través de su plataforma de Twitter. Otro sobre las enseñanzas de las relaciones públicas promovidas en el contexto de la racionalización del trabajo desde una perspectiva histórica brasileña. Continúa con un análisis bibliométrico comparativo de dos revistas con el título «Journal of Public Relations Research» que aparecen en el buscador de la WoS. También un artículo que tiene como objetivo conocer qué teorías de la comunicación organizacional influencian los estudios desarrollados en Brasil y cómo son apro- 
piados en la investigación y en la enseñanza en los cursos de Relaciones Públicas, Comunicación Organizacional, Periodismo y otros ofrecidos por instituciones de enseñanza brasileñas y un estudio comparativo de modelos de relaciones públicas en 60 organizaciones del tercer sector de México, Chile, Inglaterra y España utilizando Facebook. Incluye un documento que explora el uso de la comunicación de referencia para los proyectos de construcción en Cataluña después de la aprobación de la segunda estatua de Autonomía en 1979. Otro artículo trata de identificar y caracterizar las informaciones sobre políticas públicas de sustentabilidad ambiental disponibles en las páginas web del Sistema Ambiental Paulista, del Estado de São Paulo (Brasil), accesadas por medio de la red social Facebook. Continúa con un artículo sobre las organizaciones contra el cáncer de mama que profundiza en las características de los posts de Facebook con más engagement publicados por las organizaciones internacionales contra el cáncer de mama. Otro artículo analiza el uso de la escucha organizacional como estrategia de comunicación por parte de las organizaciones en España. Y finaliza con un artículo sobre los niveles de responsabilidad de los medios en sus relaciones con las minorías, centrado en la epilepsia y el autismo.

\section{REVISTA INVESTIGACIÓN BIBLIOTECOLÓGICA \\ (México: Universidad Nacional Autónoma de México, vol. 32, núm. 77, 2018)}

La revista científica mexicana editada por el Instituto de Investigaciones Bibliotecológicas y de la Información de la Universidad Nacional Autónoma de México, incluye un trabajo que tiene como objetivo es analizar el impacto de los artículos más citados que han sido publicados en las dos revistas españolas de Biblioteconomía y Documentación incluidas en el Journal Citation Reports (JCR), así como determinar la influencia de las autocitas en su índice h. Un artículo que presenta la actividad de Espasa-Calpe Mexicana desde su origen en 1927 hasta el final de la dictadura del general Franco en 1975, analizando las distintas fases de su desarrollo con el objetivo específico de aportar nuevos datos para la historia de la edición en ambos países. El objetivo del artículo titulado «La enseñanza por la investigación: interlocuciones con Paulo Freire en la docencia en biblioteconomía» es relatar y confirmar la propuesta freireana de enseñar aprendiendo al ser aplicada en el contexto de la Ciencia de la Información y discurre acerca de la práctica de la investigación aliada al diálogo y al intercambio de informaciones, procedimientos adoptados por un docente de Biblioteconomía en una universidad.

\section{REVISTA LATINA DE COMUNiCACIÓN SOCIAL}

(Tenerife: Universidad de La Laguna, núm. 73, 2018)

La revista aborda investigaciones sobre el fandom televisivo y construcción de identidad analizando comentarios de las fans españolas y los community managers en foros 
y redes sociales dedicados a la ficción televisiva española. Incluye un artículo sobre el individualismo como estrategia improvisada en la dispersión de vídeos yihadistas en YouTube y otro centrado en el caso de Verdeliss y las marcas bajo el título «La profesionalización de los youtubers». Continúa con un estudio que explora el papel de la homofilia en la argumentación y la interacción comunicativa en Facebook. En otro artículo se analizan las industrias culturales y la composición de los personajes en las series de animación infantil emitidas en España. También trata sobre la crisis económica y financiera de 2008, que ha sido un tema argumental recurrente en numerosos productos culturales contemporáneos, tales como ensayos, novelas, cómics, trabajos fotográficos, films documentales, películas de ficción, series de televisión, web-documentales, videojuegos, etc. bien para analizar las causas de este fenómeno o sus consecuencias en la actualidad.

Presenta además unos ítems-parámetros para el diseño de una escala de detección temprana y cribado sobre el uso problemático de Internet para actividades sexuales en los adolescentes y jóvenes, que nos informe si un individuo tiene o no un problema, o riesgo de tenerlo respecto a la actividad sexual en Internet. En otro trabajo se investiga sobre si el uso de un formato narrativo estructurado en Facebook produce un mayor impacto en el conocimiento sobre el VPH y en las actitudes y conductas más preventivas, que presentando la misma información en un formato no narrativo, más tradicional y expositivo. La revista también recoge dos artículos titulados «El uso de los medios de comunicación y la elaboración cognitiva: El papel mediador de la eficacia mediática» y «Las Industrias Culturales y Creativas (ICC) en las comunidades autónomas españolas centrado en Cataluña». Plantean además, si la cultura digital continúa las pautas de la cultura de masas difundida por medios analógicos o si inicia un nuevo modelo cultural en las redes digitales. A continuación se analiza el impacto de la televisión a la carta en las audiencias del prime time en España. También incluye un artículo sobre la representación composicional de la intermedia agenda-setting de los principales grupos de medios y partidos políticos en las elecciones generales españolas de 2015 y una investigación que analiza el uso de los recursos de la web 2.0 y el tratamiento informativo de 6 revistas sobre divulgación científica y pseudociencia. Seguidamente se analizan los contenidos del programa radiofónico «Complementarios» de la cadena pública Radio 5 como muestra de la preocupante pandemia de discursos pseudocientíficos que se distribuyen desde los medios de comunicación. Sigue con un trabajo que pretende analizar y comparar los actos de violencia emitidos en televisión española durante franjas horarias con diferente grado de protección a la infancia y otro sobre la implantación de la innovación en los cibermedios españoles analizando las percepciones de los periodistas. En otra investigación analiza el fenómeno de la discriminación de precios por género y su presencia en el ámbito de los productos de cuidado personal, poniendo en relación la construcción de la identidad de género en los medios de comunicación con la oferta de productos dirigidos a hombres y mujeres. El tratamiento que le otorga la publicidad audiovisual a la diversidad sociocultural se analiza en otro ar- 
tículo, centrándose particularmente en los rasgos fenotípicos. Las relaciones públicas y los desastres naturales se abordan describiéndose el papel que la gestión de la comunicación y las relaciones públicas cumplieron en el sismo del 19 de septiembre del 2017 en México. Continuando en ese país tratan las perspectivas de los estudiantes mexicanos sobre competencias en TIC, definidas por género. En otro trabajo y tras una base metodológica descrita a través de una viñeta se muestra un breve planteamiento teórico de la cuestión en el que se divide al mensaje periodístico en coyuntural y estructural. A continuación se abordan temas como «De los mass media a los medios sociales: reflexiones sobre la nueva ecología de los medios» o «Experiencia de usuario y medios de comunicación». Este último trabajo tiene por objetivo determinar el número óptimo de clics que los usuarios están dispuestos a hacer para llegar a la información que buscan. Una investigación aborda las estrategias del festival «Camerimage» para potenciar la fotografia cinematográfica, los estilos fotográficos impulsados y su repercusión en la carrera de los directores de fotografía. Otro estudio pretende determinar la evolución de la comunicación turística 2.0 en Ecuador desde la gestión de las empresas que ofrecen productos y servicios turísticos. También se recoge la contribución del futurólogo estadounidense Alvin Toffler al imaginario teórico y conceptual de la comunicación.

Se analiza la calidad de la infografía impresa en los diarios de información general de la Comunidad Autónoma del País Vasco a raíz del atentado yihadista del 17 de agosto de 2017 perpetrado en Barcelona. El trabajo titulado «Audiencia televisiva y memoria: estudio de caso de la ficción Los archivos del cardenal en Chile», se explica que la serie de ficción televisiva del canal público TVN en Chile; Los archivos del cardenal, causó impacto de impresión, recuerdo y dramatismo en los espectadores al revivir con sus dos temporadas en el 2011 y 2014, acontecimientos ocurridos en Chile durante la dictadura militar. Otro conflicto es el que se aborda en el trabajo «El tratamiento del postconflicto colombiano por medio de infografias y visualizaciones de datos». El análisis de los usos de la fotografía en la red social $\mathrm{Fa}$ cebook, a través de un estudio de 200 perfiles de Facebook de personas adultas, abre la opción de conocer cuáles son las fotografias más utilizadas para la conformación de la imagen del perfil y qué herramientas utilizan los usuarios que ya han dejado atrás la adolescencia. La eficacia en la comunicación de las ONGD y el uso de Facebook en campañas de emergencia explican que las redes sociales son la base de la eficacia de la comunicación de las ONGD. El objeto de estudio es determinar el papel de dichas redes y analizar las características de los mensajes en Facebook, la red social más utilizada en campañas de emergencia. Sigue con un análisis crítico de corte cuantitativo sobre la tendencia a la externalización de la producción en TVE. También presenta un estudio bibliométrico de las revistas de relaciones públicas catalogadas en las bases de datos Social Sciences Citation Index-Communication-Journal List y de las de estrategia del Social Sciences Citation Index-Management-Journal List, propiedades de Thomson Reuters. Se abordan temas como el desarrollo de las productoras audiovisuales en Extremadura en el siglo xxi o la evaluación de la reputación de 
los medios de comunicación realizado en Castellón en 2017 en el ámbito del proyecto I+D «La reputación de los medios de comunicación en España y en Europa». También el uso por los periodistas de las recomendaciones de la OMS para la prevención del suicidio. El caso del periódico $A B C$. Las claves del éxito de las adaptaciones de producciones televisivas españolas en el extranjero se abordan desde un análisis de los valores de producción de la serie española de RTVE «Los Misterios de Laura», adaptada por la NBC en Estados Unidos bajo el título «The Mysteries of Laura» (NBC, 2014-2016).

Mediante un estudio sobre los jóvenes universitarios en Colombia se explica la relación entre el consumo de medios digitales, la participación y la eficacia política. El objetivo del siguiente trabajo es contrastar puntos de vista, temáticas, influencias y publicaciones entre periodistas españoles y latinoamericanos. Otro se centra en la labor de periodistas y medios en pro de la libertad de expresión y en contra de la censura en un escenario post primavera árabe y un también un mapa de los cibermedios de España en 2018. En «El imaginario sociodemográfico de las mujeres en los 'mercados' sexuales y eróticos en la filmografia marroquí» se analiza y ofrece una primera base de datos sobre la representación de los mercados sexuales y eróticos de la filmografia marroquí, centrándose en las figuras femeninas: su caracterización sociodemográfica, roles desempeñados y carácter liminar de las prácticas de sexo transaccional representadas. Como una forma de personificación de la marca, otro trabajo analiza la presencia de la figura del portavoz en sus distintas modalidades y el uso que se hace de ellos en la publicidad radiofónica. La importancia y singularidad del movimiento de las radios libres en España durante la Transición Española. Este número incluye artículos sobre los menores influyentes en YouTube bajo el título «Un espacio para la responsabilidad», sobre la fuga de los millennials de la televisión lineal, sobre las mujeres cineastas y mujeres representadas en el cine comercial español (20012016), sobre la aplicación de la crítica de los dispositivos a la cena performativa de la ópera «El Somni» de El Celler de Can Roca y Fran Aleu y finaliza con un artículo sobre la construcción de la identidad infantil en el Mundo Disney y otro sobre la transparencia e información pública en las televisiones del Ecuador centrado en Ecuavisa y TC Televisión.

\section{REVISTA MEDITERRÁNEA DE COMUNICACIÓN}

(Alicante: Universidad de Alicante, vol. 9, núm. 2, 2018)

La revista que publica desde el 2010 divulga dos monográficos. El primer monográfico, sobre Educomunicación y promoción de la salud explora la eficiencia de los hospitales españoles en producción científica como indicador de transferencia de Conocimiento, la competencia tecnológica y habilidades relacionadas con las Tecnologías de la Información y la Comunicación (TIC) de los adultos maduros, las construcciones del género en tiempos de Internet como modos de expre- 
sión y riesgos percibidos en las redes sociales durante la niñez o la gamificación y transformación de la escuela. También se abordan temáticas prosociales e impacto de una intervención educativa Flipped Classroom relacionada con la promoción de la salud mediante la creación relatos audiovisuales y un estudio sobre la importancia de Informar y concienciar sobre cáncer basado en el caso de la Asociación Española Contra el Cáncer en Facebook. Finaliza con un artículo sobre la representación de la salud en la publicidad audiovisual de Manos Unidas mediante un análisis de contenido de las campañas institucionales de 1995 a 2017. El segundo monográfico, que versa sobre la generación LED abarca los siguientes temas: la educomunicación, competencias mediáticas y smartphones divulga el contenido sobre el uso crítico de los medios en la formación universitaria. También las competencias parentales positivas y Smartphones: Diagnóstico en el contexto familiar sobre la generación millennial. Continúa con las autorrepresentaciones y rasgos comunicativos de las interacciones de jóvenes en Tinder. Se presenta la aplicación móvil como estrategia de educomunicación orientada a la eliminación del castigo físico en menores en el caso de Hands up y también la validez de la publicidad como recurso en la Educación Ambiental. Finaliza con un análisis de la (d)Eficiencia en el uso del smartphone y las redes sociales en la acción pastoral de los agentes de la Iglesia de Aragón. Incluye otros artículos fuera de los monográficos, que describen el consumo literario como experiencia compartida en entornos transmedia basado en el club de los incomprendidos, la interacción de las audiencias con las noticias en los portales digitales de los principales diarios de Perú, la transformación de la docencia mediante los usos de las plataformas de e-learning en la educación superior presencial y la autonomía mediática del alumnado de Educación Infantil y Bachillerato en el caso español. Además presenta un artículo sobre la producción y edición del vídeo de bajo presupuesto en «Lost Ones» (Joan Thiele) de Giada Bossi y otro sobre formatos y sectores en el branded content musical (videoclip y moda, popstars de la musicidad). Finaliza con un análisis sobre la danza contemporánea y sincronía musicovisual en el videoclip musical actual.

\section{SCIRE}

(Zaragoza: Universidad de Zaragoza, vol. 24, núm. 1, 2018)

La revista que versa sobre la representación, normalización, tratamiento, recuperación y comunicación de la información y el conocimiento, aborda la representación, información, identificación y valoración del libro antiguo desde el punto de vista de bibliotecarios e investigadores ante un problema común. En segundo lugar presenta un estudio para trazar un mapa y discutir el conocimiento producido sobre análisis de contenido en la Ciencia de la Información brasileña. Continúa con la información como tema en el derecho y en la ciencia de la información, un estudio comparativo a partir de la realidad brasileña. Y también las confluencias filosóficas para la clasificación de las artes. Lo siguiente es un análisis sobre las influencias filosófi- 
cas de la clasificación bibliográfica de William Torrey Harris, reconocida por la literatura del área, como la fuente más inmediata utilizada por Dewey para la creación de su sistema. A continuación presenta un estudio que tiene como objetivo analizar las interrelaciones e interdisciplinariedad del Diseño de la Información, Ciencia de la Información y la Organización del Conocimiento. Seguidamente se analiza la evolución del Conjunto Mínimo Básico de Datos (CMBD), un sistema de información hospitalario desde sus inicios hasta su última versión denominada Registro de Atención Sanitaria Especializada (RAECMBD). Para finalizar, se presenta la trayectoria académica de Hope A. Olson, cuya producción bibliográfica se caracteriza por una marcada crítica hacia los principios de universalidad y jerarquía presentes en las clasificaciones documentales.

\section{Signo y PENSAMiento}

(Bogotá: Pontificia Universidad Javeriana, vol. 37, núm. 72, 2018)

Bajo el título «Avances» el número recoge artículos sobre algunos cruces textuales del discurso bíblico y político, producidos en el género discursivo periodístico de opinión «Columna», a partir de un hecho noticioso y político contingente como el "Caso Caval», que involucra a la familia presidencial chilena. Continúa con un estudio de la participación digital en la cultura que pretende contribuir a la comprensión de la participación digital en la cultura del entorno cubano. En tercer lugar, se analiza de manera crítica un conjunto de discursos, en los cuales, el concepto de diversidad cultural ha sido valorado positivamente. Para finalizar, un artículo titulado «Bibliotecas, internacionalismo y paz» en el que se explica el surgimiento de los movimientos internacionalistas y pacifistas en el siglo XIX y su relación con la llegada moderna de la bibliotecología y la ciencia de la documentación. También se discute el rol de las bibliotecas en la consolidación de la paz.

\section{Telos: Cuadernos de Comunicación e InNOVACiÓN (Madrid: Fundación Telefónica, núm. 109, 2018)}

En la entrevista que contiene el número el reconocido inventor Jaron Lanier expone su visión sobre la capacidad de la realidad virtual para iluminar y ampliar nuestra comprensión del momento y urge a revisar el universo digital que estamos construyendo. Su cuaderno central está dedicado a las cuestiones éticas que plantea el progreso, a las motivaciones y a los objetivos por los que el humano busca constantemente el mejoramiento de sí mismo y de su entorno. Y desde diferentes perspectivas se reflexiona sobre las razones por las que nos esforzamos en idear, investigar, desarrollar e innovar si no la búsqueda de la felicidad y el bienestar; el logro de la equidad y el bien común. Los autores apuestan por un desarrollo que ponga los valores de la humanidad por encima de todo. 


\section{Trípodos: Llenguatge, Pensament, Comunicació}

(Barcelona: Universitat Ramon Llull, núm. 41, 2017)

El número sobre la revista es un monográfico sobre el cine negro, thriller y policíaco español desde una perspectiva histórica.

En primer lugar propone una aproximación al estudio de la evolución del género en España desde sus albores hasta la actualidad, enlazándolo con la progresión histórico-política del país y de la cinematografia autóctona. A continuación se descubre cómo una parte muy importante de estas producciones tendrán su origen en las productoras barcelonesas. En el siguiente texto se expone cómo en el universo cinematográfico del thriller "Angustia» dirigido por José Antonio Nieves Conde se logra hacer copartícipe al espectador de la inquietud y la desazón experimentada por una subjetividad alienada. Además se explican las singularidades y rupturas del cine criminal español a través de «Los ojos dejan huellas» (1952). En el siguiente artículo se analiza el tratamiento y promoción del filme «El cebo» (1958), desde una perspectiva aleccionadora. También un análisis sobre el cine de temática policíaca de la Transición española o una investigación sobre el acercamiento formal de Antonio Drove al cine negro en "La verdad sobre el caso Savolta» (1978) que choca con prácticamente todo lo visto anteriormente en el cine español según la crítica de la época. «Asesinato en el Comité Central», de Vicente Aranda (1982) es un thriller político que en su momento no tuvo ni fortuna crítica ni éxito de taquilla y que, en parte, fue repudiado por su propio director que con el tiempo nos permite proceder a una relectura que valore su clara raíz esperpéntica.

En un estudio comparativo entre «Plenilunio» y «Caníbal» se analiza el psicohorror en el cine español del nuevo milenio. Este número también incluye artículos sobre la polivalencia periodística en las agencias de noticias AFP, EFE, ANSA y ACN con el objetivo de hallar los límites que no deben traspasarse para evitar que la sobrecarga de trabajo reduzca la capacidad de informar y un trabajo que estudia la estrategia digital con audiencia social desarrollada por las principales formaciones políticas durante el debate electoral del 13 de junio de 2016 retransmitido por $17 \mathrm{ca}-$ denas de televisión, fue el quinto debate más visto en la historia de España y alcanzó 1,8 millones de tuits. 